\title{
A cidade como negócio
}

Inaiá de Carvalho. Universidade Federal da Bahia, Salvador de Bahia, Brasil. Gilberto Corso-Pereira. Universidade Federal da Bahia, Salvador de Bahia, Brasil.

RESUMO | As transformações atuais das grandes metrópoles vêm adquirindo um certo destaque na agenda da pesquisa urbana. Inserindo-se nesse debate, este artigo analisa o novo protagonismo do capital imobiliário no desenvolvimento dessas cidades, a partir de um estudo de caso sobre Salvador, a primeira capital e hoje a terceira maior cidade brasileira. Para tanto, o texto começa abordando a literatura sobre os impactos das transformações associadas à globalização sobre essas cidades. Destaca, entre as mesmas, o abandono por parte do Estado de boa parte de suas funções tradicionais de planejamento e gestão urbana, que vêm se transferindo para atores privados, levando a uma afirmação da lógica do capital imobiliário na produção e reprodução da cidade. Mostra, a seguir, como isto vem se dando no caso de Salvador, com impactos bastante adversos sobre a estrutura e a vida urbana.

PALAVRAS CHAVE | áreas metropolitanas, mercado imobiliário, transformações sócioterritoriais.

ABSTRACT | The current transformations of large cities have acquired a certain relevance in the urban research agenda. This article analyzes the new role of real estate capital in the development of large cities, analyzing the case of Salvador, the first capital and now the third largest Brazilian city. The text begins by discussing the literature on the impacts of changes associated with globalization in this type of cities. Among these changes, this paper highlights the abandonment by the State of much of its traditional functions of planning and urban management, which have been transferred to private actors, leading to an affirmation of private interests in housing production and reproduction of the city. This article shows how this process has ocurred for Salvador's case, with very adverse consequences for its urban structure and urban life.

KEY WORDS $\mid$ metropolitan areas, real estate market, socio-territorial transformations.

Recibido el 31 de agosto de 2011, aprobado el 4 de noviembre de 2011

E-mail: Inaiá de Carvalho, inaiammc@ufba.br | Gilberto Pereira, corso@ufba.br 


\section{Introdução}

Este trabalho se propõe a analisar o protagonismo atual do capital imobiliário no desenvolvimento das grandes metrópoles brasileiras, a partir de um estudo de caso sobre Salvador, a primeira capital e a terceira maior cidade do Brasil nos dias atuais, com uma população de 2.676.606 habitantes. Baseando-se em bibliografia especializada, documentos oficiais, fotos aéreas, notícias publicadas pela imprensa, material publicitário e entrevistas com vereadores, membros do Ministério Público e outros informantes qualificados, ele se insere no debate sobre a conformação espacial das grandes metrópoles, que vem assumindo um certo destaque na agenda atual da pesquisa urbana.

Como se sabe, esse debate foi iniciado sob a influência das reflexões de autores como Sassen (1991), Veltz (1996), Borja e Castels (1997) ou Marcuse e Kempen (2000) sobre a nova ordem social e espacial que estaria sendo produzida nas grandes metrópoles, pelo processo de globalização, ainda que no caso do Brasil e da América Latina suas principais hipóteses não venham sendo confirmadas. Pesquisas desenvolvidas sobre as grandes metrópoles brasileiras e latino americanas têm evidenciado que, embora quase todas as grandes cidades sejam de alguma forma tocadas pelo processo de globalização, seu envolvimento depende da natureza e alcance desse processo (que não é uniforme nem converge para um modelo único de cidade), e sua dinâmica é definida pela continuidade/transformação, onde o préexistente condiciona a irrupção do novo, que, em muitos casos, já havia começado a se esboçar no passado (De Mattos, 2004). Notadamente, no que diz respeito às estruturas urbanas, como ressalta Préteceille (2003), não podem ser interpretadas como um efeito direto das transformações recentes, pois constituem uma herança histórica dos efeitos de economia e da sociedade no longo prazo, centralizada tanto nas estruturas materiais do espaço construído, como nas formas sociais de valorização simbólica e de apropriação.

Por isso mesmo, estudos efetuados sobre as grandes metrópoles do Brasil, do Chile, do México, do Uruguai e da Argentina têm constatado uma relativa estabilidade das suas estruturas social e urbana ${ }^{1 .}$ Mas essa estabilidade não impede que se verifiquem algumas transformações comuns, com modalidades e alcances específicos em cada cidade. Destacam-se, entre as mesmas:

- mudanças na estrutura econômica e social dessas cidades, associadas à reestruturação produtiva e a outras exigências da nova fase de desenvolvimento capitalista, como uma relativa desindustrialização, um avanço e maior diversificação das atividades terciárias, a flexibilização e precarização das relações de trabalho, o aumento do desemprego, das desigualdades sociais ou da pobreza (mas sem levar à uma dualidade), com impactos adversos em termos da conflitividade e da violência;

1 Ver, por exemplo, Ribeiro, 2004; Taschner; Bógus, 1999; De Mattos, 2004 e 2010; Shapira, 2000; Janoschka, 2002; Duhau, 2001 e 2005; Bayon, 2008; Cordera; Kuri; Zicardi, 2008; Gonzalez, 2010; Veiga, 2010. 
- a expansão dessas metrópoles para as bordas e para o periurbano, assim como o descenso demográfico, o empobrecimento ou a própria deterioração de antiga áreas centrais, paralelamente ao surgimento de novas centralidades, muitas vezes associada à edificação de equipamentos de grande impacto na estruturação do espaço urbano, como shopping centers, grandes hospitais, complexos empresariais ou centros de convenções;

- a difusão de novos padrões habitacionais e inversões imobiliárias destinadas aos grupos de alta e média renda, com a proliferação de condomínios verticais e horizontais, fechados e protegidos (implantados, algumas vezes, em áreas antes populares), com dispositivos explícitos de separação física e simbólica, como cercas, muros e sofisticados aparatos de segurança, ampliando progressivamente a auto-segregação dos mais ricos, a fragmentação e as desigualdades urbanas;

- o abandono, por parte do Estado, de boa parte das suas funções tradicionais de planejamento e gestão urbana e metropolitana, que vêm se transferindo para atores privados, levando a uma afirmação crescente da lógica do capital imobiliário na produção e reprodução dessas cidades, com impactos decisivos sobre a paisagem e a vida da sua população.

No que tange a essa última transformação, vale ressaltar que, embora a mercantilização do crescimento urbano constitua uma tendência congênita de urbanização capitalista, isto agora tem um caráter e impactos bem mais amplos, analisados por autores como Duhau (2001) e De Mattos (2010a e 2010b), e associados às referidas transformações. A difusão das tecnologias de comunicação e informação, a ampliação da malha viária e o uso crescente do automóvel, têm viabilizado novas formas de mobilidade e conectividade, e reduzido o peso do fator distância, provocando mudanças no comportamento locacional de famílias e empresas, a escolha de lugares mais distantes do centro urbano e a ampliação e reconfiguração do território metropolitano. Associando-se à exigência de novos espaços e infraestrutura para abrigar as novas atividades hegemônicas (como serviços financeiros, consultoria, informática ou assessoria) e para o turismo e para a moradia, o consumo e o lazer das camadas de alta e média renda, tem demandado a ampliação e reconfiguração da malha urbana e estimulado a construção civil.

A isto se soma a aceleração dos fluxos de capital produzidos pela globalização financeira, sob o estímulo das políticas de liberalização econômica (parte não desprezível orientada para a inversão imobiliária) e um novo enfoque de governança que se rege pelos princípios de subsidiariedade estatal, ênfase nos mecanismos de mercado e busca de competitividade urbana.

Em muitas cidades da América Latina a governança vem assumindo um novo significado, sob a influência do ideário neoliberal, de agências multilaterais e de alguns consultores internacionais, e com o abandono da matriz de planejamento racionalista e funcionalista e a adoção do denominado "empreendedorismo urbano”. Discutida por autores como Harvey (2005), Vainer (2002), Maricatto (2002), 
Gonzalez (2010) e De Mattos (2010a e 2010b), essa governança se inspira em conceitos e técnicas oriundas do planejamento empresarial, compreende a cidade principalmente como um sujeito/ator econômico e vê como eixo central da questão urbana a busca de uma competitividade orientada para atrair os capitais que circulam no espaço sem fronteiras do mundo globalizado, de forma a ampliar os investimentos e as fontes geradoras de empregos.

Para o alcance desse objetivo, compete ao poder local utilizar estratégias de marketing para a promoção e "venda" da imagem de sua cidade, considerar as expectativas e demandas do mercado nas suas decisões e ações e criar um ambiente favorável e atrativo para os investimentos. Entre outros aspectos, isto envolve uma mercantilização e espetacularização da cidade, com a edificação de grandes equipamentos culturais, a gentrificação de certas áreas, a atração de grandes eventos internacionais, o estabelecimento de parcerias público/privadas e uma maior flexibilidade e liberdade para a operação do capital. Como bem ressalta De Mattos (2010), essas orientações favorecem especialmente os investimentos imobiliários, com quem o poder local vem tendendo a negociar as condições para a sua maior expansão, incluindo entre as mesmas, a flexibilização das normas relativas ao parcelamento e uso do solo e os códigos de edificação, antes estabelecidos para orientar e controlar o desenvolvimento urbano. Com a restrição dos recursos, inversões e ações estatais, a ênfase nos mecanismos de mercado e a nova primazia do capital imobiliário, esse desenvolvimento se consolida dentro de uma lógica mais estritamente capitalista e ignorando, deixando em segundo plano, ou até contrariando, as necessidades e demandas mais amplas da maioria da população, como será visto no caso de Salvador.

\section{A urbanização e metropolização de Salvador}

Salvador foi fundada pelos portugueses em 1549, com funções político-administrativas e mercantis, e sediou o Governo Geral do Brasil até 1763 como a cidade mais importante do país. Mas, com a transferência da capital do país para o Rio de Janeiro, ainda no período colonial, o declínio da base exportadora local, a industrialização, e o predomínio econômico do centro sul do país, Salvador foi afetada negativamente, passando por um longo período de estagnação econômica e populacional.

A partir de 1940, contudo, a cidade experimentou um crescimento que ampliou a demanda de moradias e a pressão sobre a estrutura urbana. Como a sua estrutura fundiária era marcada pela concentração da propriedade do solo, isto inibiu a abertura de novas áreas para a ocupação, penalizando principalmente as parcelas mais pobres da população. Já que a cidade urbanizada não oferecia espaços habitacionais compatíveis com a sua (carência de) renda, multiplicaram-se as "invasões", como passaram a ser designadas as áreas de habitação popular que se formaram ou cresceram por "ocupação coletiva direta” de famílias sem recursos e sem moradia, à revelia do proprietário fundiário, sem consentimento, intermediação ou comercialização (Souza, 2008). Posteriormente, com o crescimento econômico e a modernização da 
cidade, e a consequente valorização do solo, elas começaram a ser vistas como um problema, passando a ser reprimidas e realocadas pelo Estado em áreas periféricas desocupadas e distantes, o que contribuiu decisivamente para a conformação do padrão de ocupação e segmentação do espaço urbano.

$\mathrm{Na}$ referida década, Salvador também foi objeto do que pode ser considerado como sua primeira experiência em planejamento urbano, com o surgimento em 1943, do Escritório do Planejamento Urbanístico da Cidade do Salvador (EPUCS), coordenado pelo engenheiro Mário Leal Ferreira. O plano por ele elaborado, fruto de anos de trabalho, era bastante ambicioso e avançado para a época, tratando a cidade de uma maneira abrangente, cobrindo desde aspectos físicos e geomorfológicos, a variáveis econômicas e sociais (Órgão Central de Planejamento [OCEPLAN], 1976). A Figura 1 mostra os logradouros públicos na Salvador dos anos 40, basicamente no entorno do Centro Histórico, com a cidade voltada para a Baia de Todos os Santos e o sistema viário, proposto pelo EPUCS, baseado na abertura de corredores de tráfego nos vales, projeto que foi implantado quase vinte anos depois, estruturando a Salvador contemporânea.

\section{FIGURA 1 | Sistema viário existente e proposto pelo EPUCS}

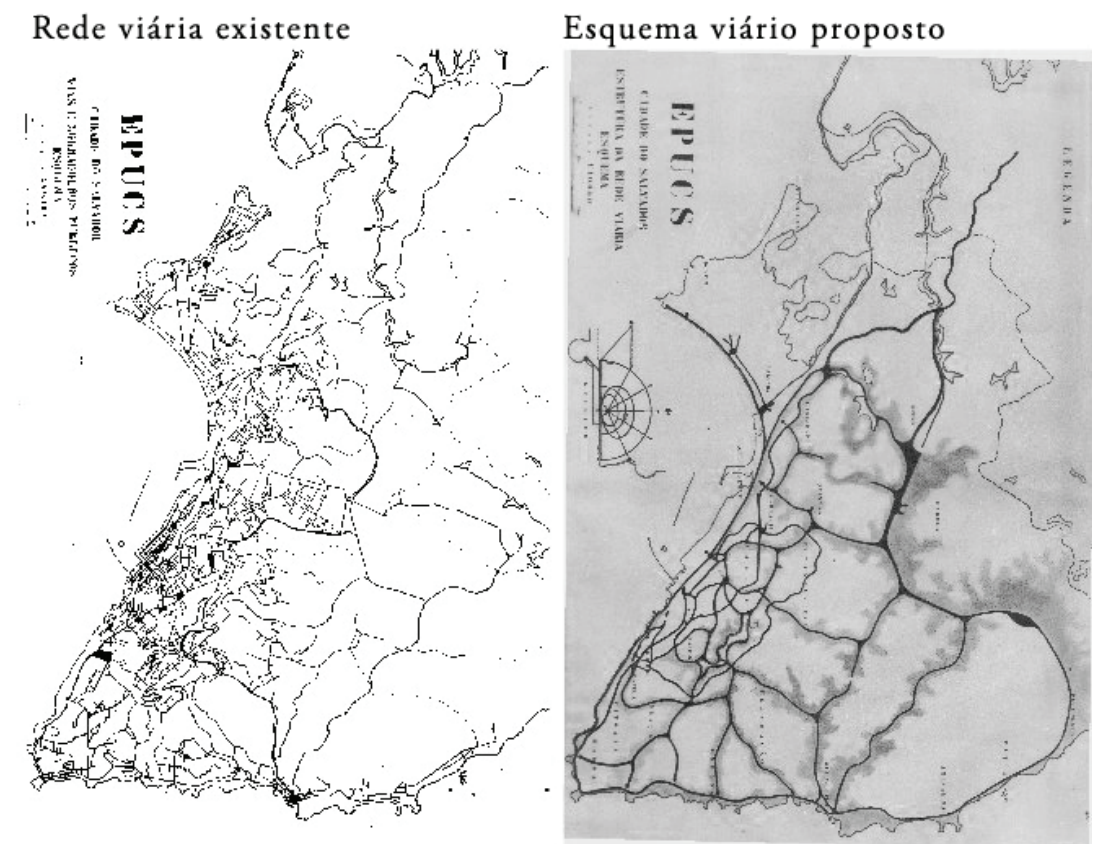

fonte Prefeitura Municipal de Salvador, 1976. ElaboraÇão E adaptaÇão dos autores.

Na década de 1950, a descoberta e exploração de petróleo em municípios de sua área de influência (por algumas décadas responsável pela maior parte da produção nacional), estimulou o crescimento populacional e urbano da cidade. Nos anos 
1960, essa região foi privilegiada com investimentos industriais decorrentes de políticas nacionais de desenvolvimento regional e, dos anos 1970 para 1980, os esforços desenvolvimentistas do governo federal para complementar a matriz industrial brasileira, com a produção de insumos básicos e bens intermediários, levaram à implantação de um grande Polo Petroquímico e de outras indústrias no município vizinho de Camaçari.

Isto teve um impacto extraordinário sobre a velha capital baiana, convertendo a indústria no foco dinâmico da economia regional, e ampliando as articulações entre Salvador e os municípios vizinhos que sediam os novos empreendimentos, conformando a Região Metropolitana de Salvador (RMS). Os referidos investimentos estimularam o surgimento de novas atividades e a expansão e modernização de outras, propiciando um crescimento econômico vigoroso que se estendeu até os anos 1980. A estrutura social foi ampliada e diversificada, mas como as transformações assinaladas incidiram sobre um mercado de trabalho marcado historicamente por um grande excedente de mão de obra, ampliado pela atração de fluxos migratórios e pelo crescimento populacional, persistiram os problemas ocupacionais e a pobreza da maioria da população.

Além disso, incidindo sobre uma região urbana precária e incipiente, a expansão e modernização econômicas assinaladas, levaram a transformações radicais no tecido urbano. Elas ocorreram de forma rápida e abrupta nas décadas de 1960 e 1970, no contexto do regime autoritário, com a realização por parte do Estado de grandes obras que acompanharam e anteciparam os vetores de expansão urbana e uma intensa ocupação informal de famílias de baixa renda na periferia.

O sistema de avenidas de vale proposto pelo EPUCS, foi implantado a partir dos anos 60, permitindo o acesso a áreas da cidade até então inacessíveis. O planejamento urbano forneceu uma justificativa racional de modernização da cidade, articulando a expansão do sistema viário com a mercantilização das terras agora acessíveis. No mesmo período em que esse sistema se expandia, comprometida com uma modernização excludente e com os interesses do capital imobiliário, a Prefeitura de Salvador, que detinha a maioria das terras do município, passou sua propriedade para (muito poucas) mãos privadas, transferiu órgãos públicos das áreas centrais, extirpou do tecido urbano mais valorizado um conjunto significativo da população pobre, (levando seus moradores a periferias mais distantes e desvalorizadas) e tomou outras iniciativas que, juntamente com o capital imobiliário, redirecionaram a expansão da cidade e seus padrões de ocupação.

Implantada historicamente na orla da Baia de Todos os Santos e tendo crescido a partir do porto, a cidade começou a se estender para a Orla Atlântica com a expansão do sistema viário, que na década de setenta foi complementado com a abertura da denominada Avenida Paralela, que configura um vetor de expansão Sul-Norte, conectando espaços vazios mas já apropriados por empreendedores imobiliários. A partir dos anos 1970, no apogeu do Sistema Financeiro de Habitação, a cidade se espraiou e se expandiu para o norte com a implantação de conjuntos habitacionais para as denominadas "classes médias baixas" no interior do município e de lotea- 
mentos residenciais e condomínios horizontais e verticais para as camadas de mais alta renda na Orla Atlântica. A valorização dessa área e o encarecimento do solo urbano em Salvador, empurrou a população de baixa renda para o centro geográfico do município, para as bordas da Baía de Todos os Santos (aonde moradores pobres chegaram a aterrar o mar e construir suas casas sob palafitas, na conhecida invasão de Alagados, hoje urbanizada) e para alguns municípios do polo metropolitano.

Assim, a expansão e modernização de Salvador não fugiu às características mais gerais do desenvolvimento urbano no Brasil. Embora o modelo das grandes cidades europeias dominasse o imaginário de suas elites, nas condições do desenvolvimento do país (marcado pela sua incapacidade de integrar plenamente as massas urbanas e pelo seu caráter excludente), as orientações que presidiram a expansão daquelas cidades e o modelo de planejamento urbano modernista e funcionalista não chegaram a se generalizar. Definindo os padrões de ocupação e uso do solo e apoiado na centralidade e racionalidade do aparato do Estado, esse modelo estendeu-se apenas a uma parte das cidades, a denominada cidade "legal" ou "formal". Embora a maioria delas dispusesse de um Plano Diretor e de órgãos encarregados da sua aplicação, esses planos ignoravam a cidade "informal" e suas áreas de pobreza, desequipadas e desassistidas, além de questões como a circulação, a segregação e a distribuição dos serviços e equipamentos. $\mathrm{O}$ crescimento urbano ocorreu à margem desses planos, que, como assinalam Villaça (2001 e 2005) e Maricato (2002), transformaram-se em "planos discurso", com um conteúdo genérico, e restrita ou nenhuma aplicação, cumprindo um papel eminentemente ideológico e ajudando a encobrir o motor que, efetivamente, comanda os investimentos e a expansão urbana, como os grupos dominantes locais, o capital imobiliário e as empreiteiras.

É verdade que, em Salvador, os planos de desenvolvimento urbano se sucederam como em outras capitais brasileiras, fornecendo discursos técnicos competentes para uma intervenção governamental que, como foi visto, orientava-se efetivamente para uma modernização excludente da cidade, favorecendo interesses econômicos a ela ligados. Depois do EPUCS e do Plano de Mário Leal Ferreira veio a fase do "desenvolvimento industrial", com a elaboração do plano do CIA/COPEC (Centro Industrial de Aratu e Complexo Petroquímico de Camaçari), destinado a preparar o terreno para a expansão urbano-industrial da Região Metropolitana de Salvador.

Em meados da década de setenta, se inicia uma experiência de planejamento comparável à do EPUCS, com a elaboração do Plano de Desenvolvimento Urbano da Cidade do Salvador (PLANDURB), e do Estudo do Uso do Solo e Transportes da Região Metropolitana de Salvador (EUST), em um momento em que os processos de urbanização e de metropolização se aceleravam no Brasil. O plano definia áreas de proteção ambiental, propunha "vetores de expansão" e um sistema viário metropolitano, mas teve uma vigência bastante curta, sendo encerrado já em 1979. Só em 1984, a Lei de Ordenamento e Uso do Solo dele decorrente foi aprovada e, além disso, como nos demais centros urbanos do país, os dispositivos da legislação urbana se aplicavam a uma cidade ideal, não à cidade real (Maricato, 2002). No caso 
de Salvador, basicamente ao centro e a Orla Atlântica, enquanto as demais áreas se expandiam desordenadamente e à margem da referida legislação.

Esse conjunto de processos levou à conformação de um espaço urbano extremamente desigual e segregado, onde, partindo do centro tradicional, se configuram três vetores de expansão diferenciados: a Orla Marítima norte, o "Miolo" e o Subúrbio Ferroviário, no litoral da Baía de Todos os Santos. O primeiro constitui a área "nobre" de Salvador, local privilegiado de moradia, serviços e lazer, onde se concentram a riqueza, os investimentos públicos, os equipamentos urbanos, shoppings, hotéis, equipamentos médicos, parques e centros de convenções, os pontos de atração turística e os interesses do capital imobiliário, assim como as oportunidades de trabalho e de obtenção de renda. O segundo, localizado no centro geográfico do município, começou a ser ocupado com a implantação de conjuntos habitacionais financiados pelo Banco Nacional de Habitação para a chamada "classe média baixa". Como grande parte dessa área foi considerada como "não edificável" por sua enorme declividade, sua expansão foi continuada por loteamentos populares e sucessivas "invasões", com uma disponibilidade de equipamentos e serviços bastante reduzida. Já o Subúrbio Ferroviário teve a sua ocupação impulsionada inicialmente pela implantação da linha férrea em 1860, constituindo, a partir da década de 1940, a localização de muitos loteamentos populares, que foram ampliados nas décadas seguintes sem o devido controle urbanístico, com suas áreas livres também invadidas. Transformou-se em uma das áreas mais carentes e problemáticas da cidade, concentrando uma população bastante pobre e sendo marcada pela precariedade habitacional, pelas deficiências de infraestrutura, equipamentos e serviços e, mais recentemente, por altos índices de violência.

O mapa que se segue, ilustra a referida configuração, mostrando à esquerda o que foi proposto pelo EPUCS, na área central da cidade e, a partir dali, as avenidas de vale e as vias estruturantes (Avenida Paralela e BR-324) que impulsionam tanto a expansão dos segmentos "superiores" em direção ao município de Lauro de Freitas, no vetor Orla, como a expansão precária para o município de Simões Filho, acompanhando o vetor Miolo.

Já o Mapa 2 apresenta a geografia social da metrópole, baseado em trabalhos de Carvalho e Pereira (2006 e 2011) que, usando como variável central o trabalho, ou a ocupação da população economicamente ativa, mostra a distribuição espacial da hierarquia social da metrópole, caracterizando as áreas da RMS como tipos socioespaciais $^{2}$. A tipologia socioespacial proposta usou os dados do Censo de 2000,

2 Conforme a metodologia elaborada pelo Observatório das Metrópoles, os tipos propostos são: Superior, onde predominam os grandes empresários locais, dirigentes do setor público e do setor privado, ao lado dos profissionais de nível superior, autônomos ou empregados; Médio-Superior, onde o predomínio é dos intelectuais; Médio, no qual profissionais de nível superior se misturam com pequenos empregadores e trabalhadores em ocupações técnicas, de supervisão, de escritório, ocupações médias de educação e saúde e atividades similares; Popular, predominam trabalhadores manuais da indústria e do comércio, assim como prestadores de serviços com alguma qualificação; Popular inferior, conjugação desses trabalhadores com prestadores de serviços não qualificados, trabalhadores domésticos, ambulantes e biscateiros. Agrícola, com expressiva frequência de trabalhadores rurais, em áreas menos urbanizadas e com baixa densidade demográfica; Popular operário agrícola, peso relativo de trabalhadores da indústria moderna e da construção civil, em áreas de predominância agrícola. 
e mostra que o vetor Orla é predominantemente ocupado pelos tipos superiores e médio-superiores, a área do centro tradicional pelos tipos médios e os vetores "Subúrbio" e "Miolo" pelos tipos populares, configurando a fragmentação que Carvalho e Pereira (2008) denominaram como "cidade moderna, cidade tradicional e cidade precária”.

MAPA 1 | Vetores de expansão urbana. Região Metropolitana de Salvador

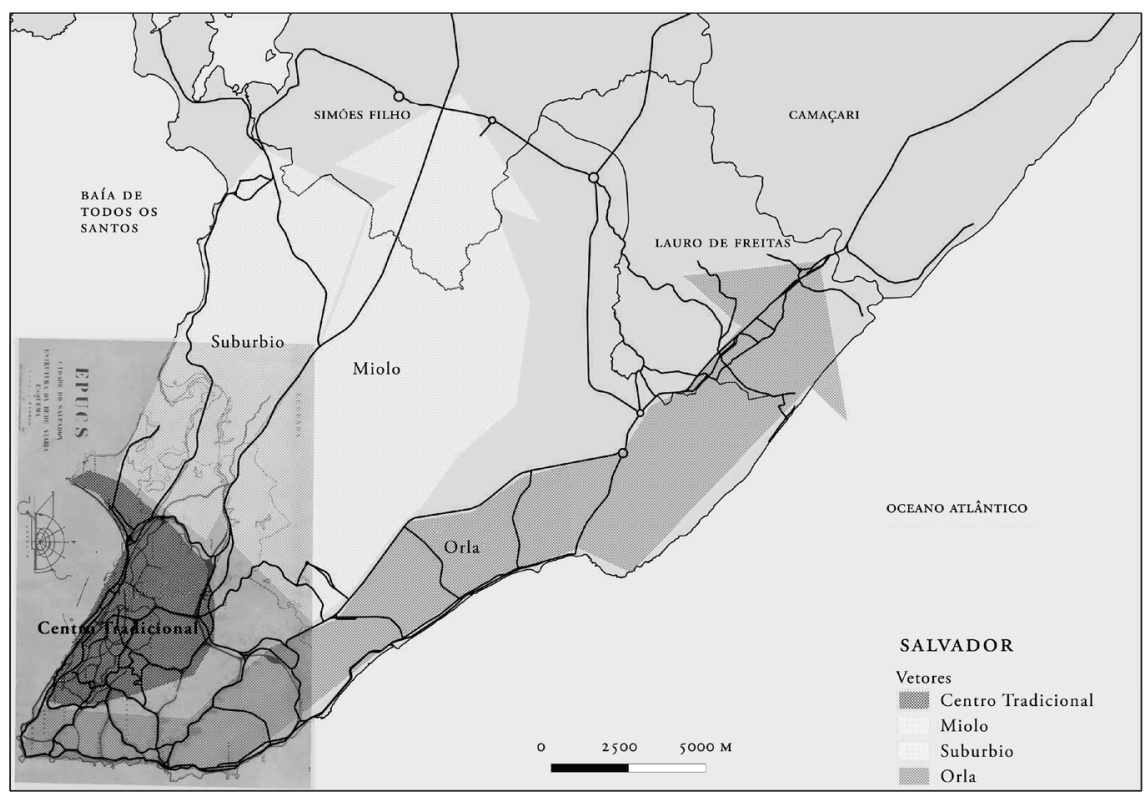

Fonte EPUCS Prefeitura Municipal de Salvador, 1976. ElaboraÇão dos autores.

A “cidade moderna” está localizada basicamente nas áreas da Orla, cujas edificações obedecem às disposições urbanísticas, têm um padrão mais alto e um acesso através do mercado formal. Na Orla, mais ao norte, predominam os loteamentos e condomínios horizontais fechados. A predominância de habitações horizontais e de baixa demanda territorial poderá ser afetada pela consolidação do processo de verticalização indicado no Mapa 3. Em alguns bairros dessa "cidade" as habitações de alto padrão se encontram principalmente em condomínios verticais, com um processo em curso de substituição dos imóveis com menor área construída, por edifícios cada vez mais altos.

$\mathrm{Na}$ "cidade tradicional" temos domicílios adequados de padrão médio, em edificações antigas e em uma mancha ocupada compacta e contínua. O processo de esvaziamento do centro tradicional persiste, mas já se pode notar um processo de transformação do espaço urbano e gentrificação de algumas áreas, acompanhado de sua valorização imobiliária.

$\mathrm{Na}$ "cidade precária" predomina a informalidade, em termos de padrões urbanísticos e de mercado, assim como a precariedade em termos habitacionais, 
particularmente no Subúrbio Ferroviário. No Miolo coexistem habitações formais (conjuntos habitacionais de baixo padrão), loteamentos populares e moradias precárias auto-construídas. A mancha de ocupação é dispersa e descontínua. Em alguns trechos da Orla, as áreas precárias aparecem como ilhas, sendo caracterizadas como Zonas Especiais, em termos de legislação urbanística.

MAPA 2 | Tipologia socioespacial. Região Metropolitana de Salvador, 2000

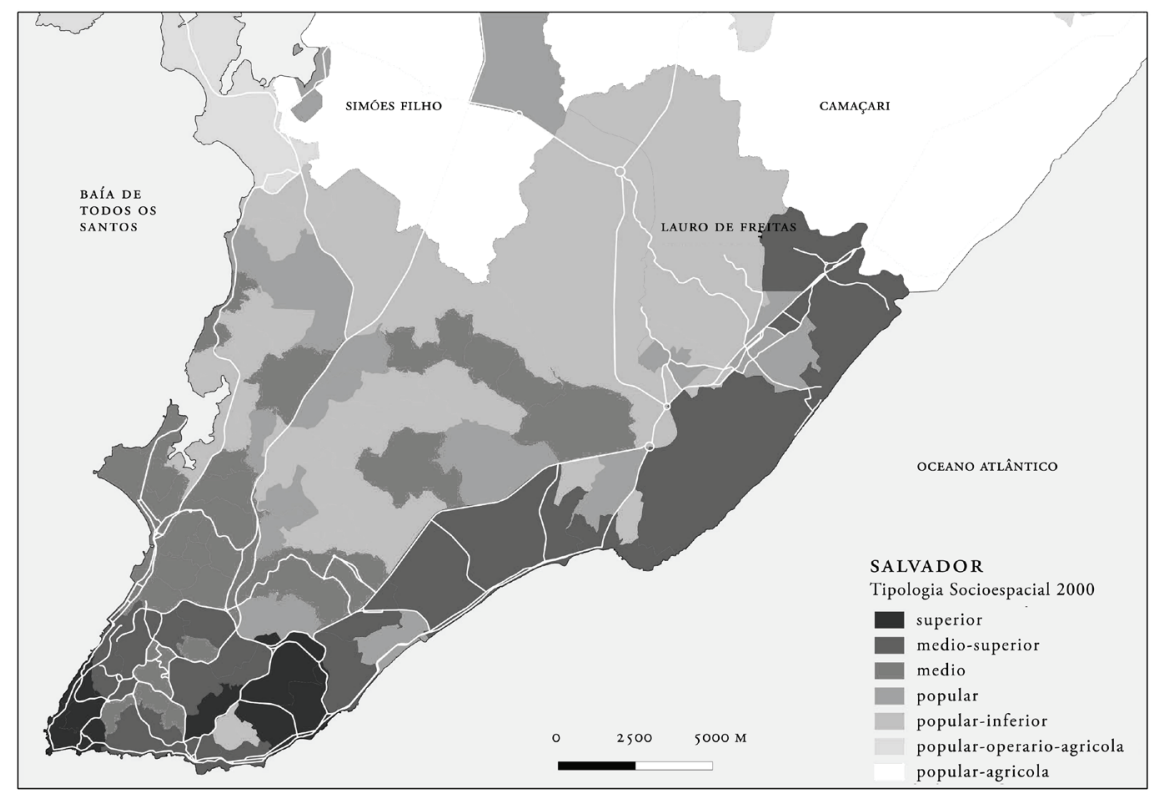

fonte Carvalho e Pereira (2008).

\section{As transformações atuais}

Ao longo dos últimos anos, Salvador vem experimentando as transformações assinaladas nas páginas iniciais deste trabalho, com destaque para o novo protagonismo do capital imobiliário na sua dinâmica urbana e metropolitana. Para um melhor entendimento desse fenômeno, é preciso levar em conta como o crescimento econômico do Brasil, no período mais recente, vem se refletindo especialmente no mercado imobiliário. As demandas por infraestrutura e novos espaços para as atividades produtivas, habitação, turismo, consumo e lazer, (especialmente para as camadas de média e alta renda), assim como a dimensão da demanda habitacional reprimida, as políticas nacionais de incentivo à habitação de interesse social, e a ampliação do crédito, do emprego e da renda, tornaram o mercado imobiliário brasileiro um dos mais dinâmicos do mundo; só o mercado de Hong Kong vem apresentando um melhor desempenho (Exame, 2010 e 2011). 
Somado à recente crise financeira e imobiliária dos países centrais, isto vem tornando o mercado nacional bastante atrativo para os capitais internacionais (The Economist, 2011 e Exame, 2011). Conforme dados da SEI, citados pela Associação de Dirigentes de Empresas do Mercado Imobiliário (ADEMI (2010b), o setor da construção civil entre junho de 2009 e junho de 2010 cresceu no Brasil 5,5\%, e na Bahia mais do que o dobro - $13,9 \%$. Somente o mercado imobiliário residencial baiano saiu de 3.151 unidades vendidas em 2005, para uma previsão de 15.000 unidades em 2010 (ADEMI, 2010a).

Nesse contexto, o capital imobiliário vem adquirindo um novo poder e protagonismo sobre o desenvolvimento das cidades, acentuados, inclusive, pelo seu atual porte e perfil, pela sua maior capacidade de intervenção no espaço urbano e pelo grau de liberdade do qual passou a desfrutar a partir das orientações do "empreendedorismo urbano".

As principais empresas atuantes neste mercado não têm mais um caráter local ou regional. Trata-se, agora, de grandes conglomerados, muitas vezes internacionalizados, que constroem obras como barragens, pontes e metrôs, e que tendo participado dos processos de privatização atuam, hoje, em ramos como a petroquímica, telecomunicações ou a limpeza pública das grandes cidades. Exemplos destas empresas são a Odebrecht e a OAS que, na sua origem, eram empreiteiras baianas e hoje podem ser caracterizadas como multinacionais presentes em diversos setores da economia, ou a Cyrela, que em dezembro de 2010 possuía 205 obras em andamento no país, e uma previsão de vendas de 8 bilhões de reais para 2011. E como o tamanho dos empreendimentos é proporcional ao dos players, essas empresas tem hoje um novo poder de interferência sobre a estrutura urbana.

\section{O novo papel do capital imobiliário}

Salvador é um caso exemplar nesse sentido. Como outras metrópoles brasileiras, a capital baiana vem experimentando um extraordinário crescimento imobiliário, concentrado nas áreas do tipo médio ou superior da Orla Atlântica, onde se encontra em curso um processo de adensamento baseado em uma verticalização crescente, pois as terras desocupadas estão se tornando bastante escassas. Estudos realizados para a Prefeitura Municipal de Salvador, com base em imagens aéreas de 2002, mostram que há poucas áreas não edificadas e sem restrições para ocupação (Pereira, 2011).

A possibilidade de ocupar espaços na orla mais ao norte tornou-se pouco atrativa pela acelerada perda de mobilidade que os habitantes da capital baiana experimentaram nos últimos anos, associada ao aumento da frota, à carência de transportes de massa e à falta ou incapacidade de gerenciamento do tráfego. Assim, o adensamento da Orla Atlântica (espaço privilegiado e mais valorizado pelas camadas de maior poder aquisitivo) vem sendo a alternativa preferida pelas construtoras, seguida pela ocupação das áreas livres da Avenida Paralela, onde persistiam resquícios da Mata Atlântica até recentemente. 
Este adensamento é baseado em uma forte verticalização, incentivada por uma legislação urbanística mais permissiva a partir dos planos diretores de 2004 e 2008, que alteraram os parâmetros de ocupação, sem apresentar critérios técnicos que justificassem as mudanças (Sampaio, 2010), confirmando a afirmação de Villaça (2001) de que a verticalização da Orla de Salvador ainda não se dera porque, até aquele momento, os interesses do capital imobiliário não haviam sido contrariados.

O Mapa 3, acrescentando os lançamentos imobiliários dos últimos três anos à tipologia habitacional elaborada por Pereira (2008) a partir da interpretação de imagens de 2002 e dados do Censo de 2000, ilustra bem a dinâmica atual. Esses lançamentos, quase todos de condomínios verticais, estão concentrados em Pituba (área já extremamente adensada) e em alguns clusters ao norte, na orla e nas bordas da Avenida Paralela, com alguns lançamentos de 2009 e 2010 cruzando essa avenida, que até então constituía a "fronteira" entre a cidade moderna e a cidade popular (Carvalho e Pereira, 2008), ensaiando um novo padrão de segregação sócio residencial.

MAPA 3 | Tipologia habitacional e lançamentos imobiliários. Salvador, 2008-2010

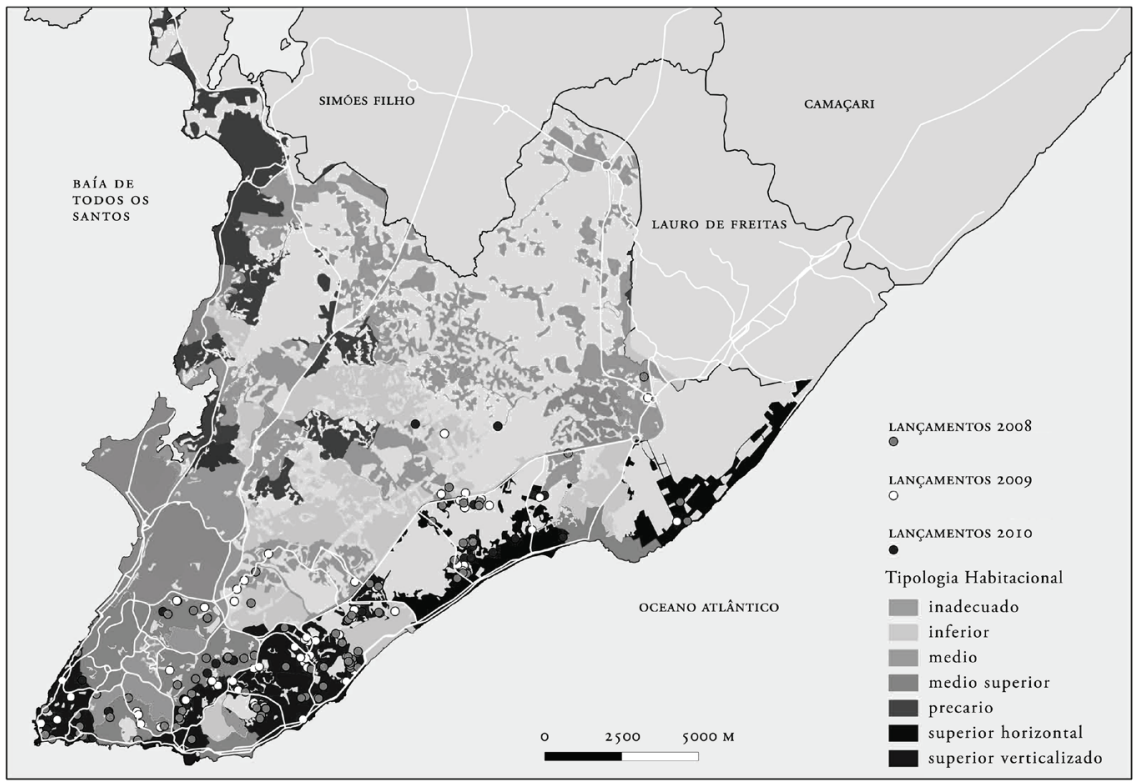

fonte Pereira (2008) e leVantamento dos autores. Elaboração dos autores.

A falta de grandes glebas desocupadas na Orla explica este movimento em direção ao interior, com o lançamento de empreendimentos em condomínios fechados, com controle de acesso, guarita, muros e demais aparatos da atual arquitetura de segurança descritos por Caldeira (2008).

A tipologia habitacional representa uma tentativa de síntese das condições habitacionais, usando como indicadores variáveis construídas a partir de dados do 
censo: a relação entre número de banheiros e número de domicílios, para indicar a localização de habitações de padrão mais alto (domicílios com mais de 3 banheiros) e mais baixo (número de banheiros menor que o número de domicílios); domicilio tipo apartamento e domicílios com até 3 cômodos ${ }^{3}$. Estes dados foram cruzados com o mapa da mancha edificada feita a partir da interpretação de fotos aéreas verticais de 2002. O resultado pode ser considerado como a expressão física dos processos de segregação socioespacial registrados na cidade

Conforme anteriormente assinalado, o porte dos novos empreendimentos e seu impacto sobre o espaço urbano agora também é outro. Um deles, lançado recentemente, é um condomínio (fechado) com 19 torres residenciais, 4 torres empresariais, um shopping, um hotel, um clube e um colégio particular, com 330,000 $\mathrm{m}^{2}$ de área. Outro, implantado na Avenida Paralela, que liga o centro ao aeroporto e a municípios da região metropolitana, e que já vive congestionada, ocupará 100.000 $\mathrm{m}^{2}$ e terá 18 torres com 1.138 unidades residenciais onde deverão habitar cerca de 5.000 pessoas. Com uma previsão de estacionamentos para 3.000 veículos, é fácil prever o impacto sobre a mobilidade urbana quando os mesmos estiverem nas ruas nos horários de pico, ou tentando entrar e sair do próprio condomínio, que é somente um dos empreendimentos atualmente em construção na região da avenida Paralela, onde aos condomínios verticais residenciais somam-se centros comerciais e edifícios de escritórios.

\section{A privatização da gestão e planejamento da cidade}

Por outro lado, o crescimento do poder da coalizão de interesses privados no desenvolvimento da cidade pode ser notado, inclusive, pela sua estreita e agora explícita articulação com o poder local, que passa por um desmonte das suas equipes técnicas, uma desvalorização da organização burocrática e um abandono da ênfase na esfera pública, que caracterizou propostas como as do EPUCS e do PLANDURB, como destaca Fernandes, 2010.

Esta articulação se expressou na aprovação, em 2004, de um novo Plano Diretor de Desenvolvimento Urbano, gestado e orientado para os interesses do mercado imobiliário, flexibilizando e alterando normas e instituindo outros mecanismos para facilitar (ainda mais) a apropriação por esses setores de mais valia urbana. Pouco preocupado com os grandes problemas da cidade, como a carência de infraestrutura e serviços básicos, a habitação popular, ou o transporte e a mobilidade, o Plano visou basicamente a modificação de parâmetros construtivos e a elevação do gabarito na "área nobre" da cidade, como desejavam os empreendedores imobiliários.

3 Os domicílios apontados como inadequados no mapa III, são os que estão em áreas onde a relação banheiro/domicilio é menor do que 1, ou seja, parte das habitaçōes não tem banheiro; já os registrados como precários são os que somam a esta condição um alto percentual de domicílios com até 3 cômodos. As habitações superiores são as que estão em áreas onde existe um alto percentual de domicílios com mais de 3 banheiros. A coincidência desta situação, com a predominância da variável domicílios tipo apartamento, indica as áreas de habitação superior verticalizadas. 
Seu conteúdo e aprovação foram bastante questionados, entre outros motivos, porque ignoravam as disposições do Estatuto das Cidade 4 e foi aprovado pelos vereadores na calada da noite (terminou sendo objeto de um processo por parte do Ministério Público). Mas esse processo não teve efeitos práticos pois, quando o Ministério Público ganhou a ação (quatro anos depois), o mesmo já havia sido revisado, com o mesmo tipo de motivação.

O eixo central dessa revisão foi o incremento nos parâmetros urbanísticos de aproveitamento do solo (Sampaio, 2010), aumentando a intensidade de ocupação por zona, sem apresentar estudos técnicos que justificassem as mudanças ou, ao menos, avaliassem o seu impacto social e ambiental. O resultado previsível é o aumento da segregação socioespacial e uma cada vez maior apropriação da mais-valia urbana pela coalizão de interesses privados corporativos, que se apropriam da paisagem urbana e espaços públicos, se beneficiam da infraestrutura instalada com recursos públicos e, nas atuais condições de governança municipal, podem inclusive impor à metrópole novos investimentos, projetos e operações urbanas.

Além disso, no início de 2010, a Prefeitura lançou um conjunto de projetos alinhavados frouxamente pelo denominado planejamento estratégico, "doado" por empresas do setor imobiliário à cidade, que com o pretensioso título de "Salvador Capital Mundial” (Prefeitura Municipal de Salvador, 2010), propunha um amplo conjunto de intervenções para direcionar o seu desenvolvimento, com singelas declarações do alcaide:

Recentemente apresentamos a empresários, à imprensa e à sociedade o masterplan intitulado Salvador Capital Mundial, um plano completo de reconfiguração urbana para Salvador, com 22 projetos estruturantes, incluindo novas avenidas, viadutos, requalificação da Orla Marítima, da Cidade Baixa e Península Itapagipana, elaborados por um grupo de arquitetos e urbanistas...

As diversas empresas participantes, dos setores de arquitetura, urbanismo, construção pesada e outras, contribuíram da forma que entenderam como mais eficaz para a elaboração deste trabalho. Um projeto que a Prefeitura de Salvador não teria como encomendar e pagar a famosos escritórios de planejamento urbano... (João, 2010, grifo dos autores)

Na verdade, esses projetos não formam um corpo coerente nem integram um plano único, sendo a expressão de interesses pontuais e direcionados para áreas da cidade sobrevalorizadas e saturadas (caso das áreas onde o adensamento construtivo foi alem da capacidade de suporte da infraestrutura instalada), ou para áreas do centro tradicional com menor valorização do solo e onde, como forma de viabilizar seu uso, o projeto justificaria a desapropriação dos imóveis dos atuais proprietários. Como seria de esperar, a localização destas intervenções ignora as áreas socialmente carentes da cidade, concentrando-se naquelas onde a especulação imobiliária pode ampliar seus ganhos.

4 Com o movimento pela reforma urbana e a aprovação do Estatuto da Cidade, que incorpora princípios como o direito à cidade, a função social de propriedade, a sustentabilidade ambiental e a gestão democrática, o Brasil passou a dispor de uma ordem jurídico-urbanística bastante avançada. Mas a efetivação dos princípios e dispositivos do Estatuto vem se mostrando problemática e restrita, não se traduzindo mais efetivamente nas políticas urbanas. 
Nem o detalhamento das propostas nem a identificação dos seus financiadores foram divulgados, com os projetos circulando na forma de vistosas publicações elaboradas por agências de publicidade. Mas apesar da tentativa de manipulação da opinião pública, essa "doação" teve uma repercussão bastante negativa, com pronunciamentos contrários de vereadores da oposição, da imprensa e de organizações da sociedade civil. Essa reação foi tão significativa que uma fundação ligada a empresas construtoras, que doara um dos projetos, veio a público desautorizando a sua utilização pela prefeitura, considerando-se mal compreendida e injustiçada pelas críticas.

Apesar disso, em junho de 2011, os referidos projetos continuavam online no sítio da web da Prefeitura de Salvador ${ }^{5}$, sem dados sobre financiamento (A Tarde, fevereiro de 2011), viabilidade econômica, impacto social e ambiental ou um detalhamento arquitetônico ou urbanístico que permitissem uma avaliação mais consistente. As críticas públicas, de um lado, mas principalmente a falta de articulação com os processos institucionais de planejamento da própria prefeitura, vem forçando a retirada de alguns deles, como foi o caso recente de uma ponte que havia sido projetada sobre a área que seria destinada a um parque, segundo o Plano Diretor de Desenvolvimento Urbano (PDDU) de 2008 (A Tarde, junho de 2011).

Nesse processo de flexibilização ou desrespeito às normas de uso do solo e construção, destaca-se a instituição de um instrumento urbanístico como o TRANSCON, que cria a "transferência do direito de construir" sem o mapeamento das áreas cujos direitos de construir podem ser transferidos ("áreas doadoras") para outras áreas ("áreas aptas a receber adensamento"), possibilitando a realização de qualquer operação independentemente de haver restrições urbanísticas, constituindo uma espécie de licença para transgredir qualquer norma restritiva. Os resultados para a cidade tendem a ser a maior saturação das áreas já saturadas e os problemas ocasionados pelo adensamento excessivo em termos ambientais, de infraestrutura, transportes, etc. Sampaio (2010, p. 174) mostra que uma área infraestruturada e adensada como a Pituba, recebeu 33,7 \% dos empreendimentos TRANSCON aprovados entre 1997 e 2009. Também é notável a elevação do número de empreendimentos que tem usado este instrumento após 2004, ano de aprovação do novo PDDU, revisto em 2008. Passou-se de uma média de 33,8 empreendimentos aprovados por ano entre 1997 e 2004 para 56,2 por ano a partir de 2005.

Significativamente, a estreita articulação entre o governo local e o capital imobiliário é explicitada pelo próprio órgão responsável pelo licenciamento de construção e atividades, a Superintendência de Controle e Ordenamento do Uso do Solo do Município (SUCOM). Em seu site, em 2009, constava que:

Visando o crescimento imobiliário da cidade de Salvador e estreitar o relacionamento com os empresários do ramo de construção, a SUCOM firmou na tarde desta quintafeira (06) um convênio com a Associação de Dirigentes de Empresas do Mercado Imobiliário (ADEMI). A assinatura do documento aconteceu no auditório do Empresarial Niemeyer e teve como público os associados da Ademi. (Sucom, 2009)

http:www.capitalmundial.salvador.ba.gov.br/ acesso em 19 de junho de 2011. 
Este convênio significou, segundo as próprias palavras do então superintendente, "trabalhar junto com a ADEMI (...) uma parceria como essa nasce em consonância com o novo modelo de gestão que o prefeito João Henrique vem trazendo para a cidade desde 2005". A expressão "novo modelo de gestão" pode ser traduzida como a passagem, para os setores empresariais, das atribuições do setor público local, particularmente as relacionadas ao uso e ocupação do solo urbano.

Em março do corrente ano, por ocasião do aniversário da cidade, o prefeito declarava que,

... para transformar Salvador em uma capital mundial, é preciso projetos arrojados, modernos, que integrem o meio ambiente e as edificações à paisagem urbana, garantindo a mobilidade e mais qualidade de vida para a sua população. (...) $\mathrm{O}$ projeto batizado de Salvador Capital Mundial, prevê soluções para o transporte, trânsito e crescimento da cidade. Serão abertas novas vias de tráfego, implantados sistemas modernos de transporte, revitalização da orla, requalificação e ampliação da estrutura turística.

A participação do mercado imobiliário neste processo de alavancagem do crescimento econômico de Salvador tem sido fundamental para consolidar o novo momento em que vivemos. Nos últimos anos a cidade teve alterada sua dinâmica com o ingresso de empreendimentos arrojados e de ponta, liderados por construtoras de grande porte oriundas de outros estados. A capital fervilha na área da construção (A Tarde, 29/03/2011, Caderno Muito).

Mais recentemente, a pretexto de que Salvador precisa se preparar para sediar algumas partidas do campeonato mundial de futebol em 2014, ele encaminhou à Câmara Municipal outras propostas de mudança no PDDU, alegando que "Para receber hotéis para a Copa, ainda é preciso mudar as regras" (Jornal Metrópoles, 2011).

Como se vê, com o respaldo do discurso do empreendedorismo urbano, consolida-se um processo que pode ser considerado como uma terceirização do planejamento e da gestão da cidade, ou, conforme antes mencionado, de transferência das atribuições de controle do uso e ocupação do solo e da formulação de políticas, planos e projetos de desenvolvimento urbano da esfera pública para a esfera privada. Todos os seus grandes projetos têm, em comum, a falta de transparência ${ }^{6}$, de discussão, de participação pública, com o repasse das atribuições tradicionais do Estado para uma coalizão de interesses privados - empreiteiras de obras públicas, empreendedores imobiliários, concessionários de serviços públicos, empresas de consultoria - que vêm transformando a cidade em commodity e direcionando seu desenvolvimento em função dos interesses imediatos dos integrantes dessa coalizão.

Tal ênfase na "cidade mundial" e na competitividade urbana, privilegiando a atração de empreendedores e turistas, ignora ou deixa em um plano absolutamente secundário, as necessidades mais prementes da maioria dos seus moradores e extrema a concentração dos investimentos na área mais valorizada, sem contemplar a

6 O controle e restrição das informaçōes pela prefeitura tem como resultado evitar a discussão das suas propostas, tendo sido bastante utilizados para reduzir a participação popular na tramitação do PDDU. 
inserção dos demais espaços no conjunto dos fluxos urbanos. Cada vez mais transforma a cidade em um negócio, na acepção mais crua do termo, em que uns poucos ganham, e quase todos perdem.

Alguns de forma mais direta e imediata, como os moradores do bairro de Itapagipe, que em 2009 receberam com surpresa a notícia de um decreto de desapropriação de suas antigas moradias (Decreto Municipal 19.418 de 2009) para a "revitalização" e gentrificação da área, (que passou a despertar a cobiça do capital imobiliário por sua localização nas bordas da Baia de Todos os Santos), com indenizações calculadas não pelos preços de mercado dos seus imóveis e sim pelos defasados valores do Imposto Predial e Territorial Urbano/IPTU. Os demais pelos efeitos devastadores desse novo padrão de governança sobre a cidade, onde se incluem a degradação do meio ambiente, com a destruição de diversas áreas verdes e dos últimos resquícios da mata atlântica, o aterramento de nascentes e lagoas, a criação de obstáculos à circulação dos ventos e a elevação da temperatura; a perda da mobilidade urbana e o aumento dos congestionamentos, a degradação dos espaços públicos e do patrimônio histórico-cultural da cidade, e, principalmente, o crescimento da segregação, da fragmentação e das desigualdades sociais e urbanas ${ }^{7}$.

\section{Algumas consideraçóes finais}

Como foi visto nas páginas iniciais deste trabalho, a dinâmica contemporânea do capitalismo tem levado a algumas mudanças comuns nas regióes metropolitanas, incluindo-se, entre elas, o abandono pelo Estado de boa parte de suas funções tradicionais de gestão e planejamento, e uma afirmação crescente da lógica do capital imobiliário no desenvolvimento desses centros.

Para isto tem contribuído a influência do ideário neoliberal e, mais especificamente, a difusão do denominado "empreendedorismo urbano", que enfatiza como eixo central da questão urbana a busca de uma competitividade para atrair os capitais que circulam no espaço, sem fronteiras, do mundo globalizado. Somando-se a outros fatores, esse novo padrão de governança vem propiciando um novo poder e protagonismo ao capital imobiliário, conforme analisado para o caso de Salvador, com os efeitos que foram apontados.

É verdade que, na metrópole baiana, esse fenômeno vem assumindo um caráter extremado e caricato, contrariando frontalmente os princípios e dispositivos do Estatuto da Cidade, em decorrência de certas especificidades e, principalmente, da estrutura de poder local $^{8}$. Mas ela não representa um caso isolado. Autores como De Mattos (2010b) tem constatado e refletido sobre a difusão e impactos des-

7 Nessas circunstâncias é no mínimo duvidoso que a cidade alcance os supostos benefícios desse modelo de governança, ampliando a sua competitividade e atratividade como um bom lugar para morar, trabalhar, visitar ou investir. Notase que Salvador já tem uma imagem forte e positiva, constituindo um dos destinos turísticos preferidos do Brasil, justamente por suas características em termos de beleza natural, patrimônio histórico e cultura.

8 Acossada pela precariedade habitacional, pelo desemprego e pela pobreza, uma boa parte da população soteropolitana transformou-se em presa fácil do populismo e do clientelismo político, e isto tem óbvias repercussões sobre o papel dos prefeitos, a composição e atuação da Câmara de Vereadores e a capacidade de organização e mobilização da sociedade civil. 
se novo tipo de governança nas metrópoles da América Latina. Entrevistas com membros do Ministério Público revelaram que essa instituição enfrenta problemas similares aos de Salvador em outras cidades brasileiras, e também na aprovação do Plano Diretor Estratégico de São Paulo foi aprovado um substituto com o que Villaça (2005) denomina como "emendas noturnas", não apenas pela hora da sua aparição como pela estranha especificidade de atender a interesses muito diretos do capital imobiliário?.

O tempo se encarregou de desfazer as ilusões do planejamento normativo e racionalista quanto à sua capacidade de modelar as cidades, ignorando ou minimizando determinantes estruturais e a lógica mais ampla da dinâmica urbana no capitalismo. A preocupação com o crescimento econômico e com uma maior geração de empregos tornou-se constante entre os poderes locais. Entretanto, não é certo que o caminho para o seu alcance seja tentar repetir (agora como farsa) a história de Baltimore ou de Barcelona, replicando formas e artefatos arquitetônicos difundidos e generalizados globalmente, multiplicando os "não lugares", mercantilizando e espetacularizando a cidade, transformando seus moradores em meros figurantes e entregando seu destino ao capital, sem levar em conta a preservação da sua qualidade de vida, coesão social e sustentabilidade ambiental.

O estudo de caso apresentado ilustra o protagonismo atual do capital imobiliário no desenvolvimento das grandes metrópoles brasileiras. A mercantilização do crescimento urbano não é novidade, como se sabe, mas o que está atualmente em curso em Salvador é a imposição de um padrão de governança municipal no qual, as decisões sobre o desenvolvimento urbano da metrópole não fazem mais parte das atribuições do poder público. Este opera como um ator coadjuvante do processo, referendando decisóes da esfera privada e criando condições institucionais para isto, o que inclui ajustar o arcabouço juridico-urbanistico às demandas dos novos players, com as sucessivas "revisões" ao Plano Diretor justificadas como forma de aumentar a capacidade da cidade para atrair investimentos. Neste contexto, a avaliação técnica dos impactos urbanísticos, sociais e ambientais que a implantação de grandes emprendimentos e equipamentos tenha sobre a cidade, deixa de ser um critério válido. Estes impactos se traduzem na atual falência do sistema de transporte (público e individual), degradação ambiental, destruição do patrimônio cultural arquitetônico, dispersão incontrolada do tecido urbano, adensamento das áreas já saturadas e aumento da segregação socioespacial, conforme anteriormente assinalado.

As promessas e ilusões despertadas pelo empreendedorismo urbano e os interesses ocultos atrás do seu discurso teórico procuram esconder este fato. Ainda assim,

9 Recentemente, por sugestão do SECOVI (Sindicato do Setor Imobiliário), o atual prefeito paulistano aprovou na Câmara uma lei que o autorizava a negociar o chamado "quarteirão de cultura", que se encontra em processo de tombamento, contra o parecer dos órgãos de preservação do patrimônio, repúdio dos moradores do bairro e os protestos da sociedade mais ampla. É um valioso terreno municipal, localizado em área nobre da cidade, densamente arborizado e onde estão instalados serviços que atendem a milhares de usuários, como escolas, postos de saúde, teatro e biblioteca. A entrega do terreno se daria em troca da construção de 200 creches na periferia. A negociação foi barrada pela justiça, considerando que a aplicação da referida lei poderia causar um prejuizo irreversível para a cidade, mas existem projetos com igual teor para outras áreas cobiçadas da capital paulista. (Folha de São Paulo, 08/07 e 05/08/2011). 
mesmo nas condições adversas de Salvador, tem crescido bastante nos últimos anos o número de grupos e pessoas que procuram o Ministério Público baiano para encaminhar protestos e reivindicações contra os efeitos mais imediatos e perversos das transformações analisadas, deixando patente a necessidade de ampliar os debates e as mobilizações sociais para fazer valer as disposições do Estatuto, assegurando o direito à cidade e conformando um outro padrão de desenvolvimento urbano. CEURE

\section{Referências bibliográficas}

A Tarde. Prefeitura desiste de erguer ponte sobre vale. 17/06/2011, p. B8.

A Tarde. Suspensas licenças de prédios altos na orla. 22/09/2010, p. A5.

$A$ Tarde. Um mês depois, prefeitura omite quem patrocina projetos da "Capital Mundial”. 28/02/2010, p. B2.

A Tarde, 29/02/2011. Caderno Muito.

Ademi. Revista. Ano 9, n. 43, 2010a.

Ademi. Revista. Ano 9, n. 46, 2010 b.

Bayon, M. C. (2008). Desigualdad y procesos de exclusión social. Concentración socioespacial de desventajas en el gran Buenos Aires y la Ciudad de México. Estudios Demográficosy Urbanos (El Colegio de México), 23(1-67), 123-150. Disponível em http://bit.ly/158T2dl

Borja, J. \& Castells, M. (1997). Local e global. La gestión de las ciudades en la era de la información. Madrid: Taurus.

Borsdorf, A. (2003). Cómo modelar el desarrollo y la dinámica de la ciudad latinoamericana [versión electrónica]. EURE, 29(86), 37-49. doi: 10.4067/S0250-71612003008600002

Caldeira, T. (2008). Cidade de muros crime, segregação e cidadania em São Paulo (2a ed.). São Paulo: Editora da Universidade de São Paulo (EDUSP).

Carvalho, I. M. M. de; Pereira, G. C.. (2008). (Orgs.) Como anda Salvador (2a ed.). Salvador: Editora da Universidade Federal da Bahia (EDUFBA).

Carvalho, I. M. M. de \& Pereira, G. C.. (2010) Dinámica de una metrópoli periférica en Brasil. Estudios Demográficos y Urbanos (El Colegio de México), 25(2-74), 395-427. Disponível em http://bit.ly/113ED1Y

Cordera, R., Kuri, P. \& Zicardi, A. (Coords.). (2008). Pobreza, desigualdad y exclusión social en la ciudad del siglo XXI. México: Siglo XXI / Instituto de Investigaciones Sociales, Universidad Nacional Autónoma de México (UNAM).

Duhau, E. (2005). As novas formas de divisão social do espaço nas metrópoles latino americanas: uma visão a partir da cidade do México. Caderno CRH: revista do Centro de Recursos Humanos da Universidade Federal da Bahia (UFBA, Salvador), 18(45).

Duhau, E. (2001). Las metamorfosis latinoamericanas en el siglo XXI: de la modernidad inconclusa a la crisis del espacio público. Cadernos IPPUR (Rio de Janeiro), 15(1), 41-68.

Exame. A maior alta do mundo. São Paulo: Ed Abril. edição 992, ano 45, n. 9, 2011, p.34-50.

Exame. A terceira maior alta do mundo. São Paulo: Ed Abril. edição 971, ano 44, n.12, 2010, p.24-41. 
Fernandes, A. (2010). O EPUCS e a Cidade do Salvador nos anos 40: urbanismo e interesse público. In I Encontro Nacional da ANPARQ. Rio de Janeiro: Associação Nacional de Pesquisa e Pós-graduação em Arquitetura e Urbanismo (ANPARQ).

Folha de São Paulo. Imobiliária Prefeitura S. A. 08/07/2011, p. A3.

Folha de São Paulo. Juiz barra venda de área no Itaim. 05/08/2011, p. CI.

Cuervo, L. M. (2010). América Latina: Metropoles en Mutación? Conferência preparada para o XI Seminário Internacional de la Red de Investigadores en Globalización y Territorio. Mendoza.

Harvey, D. (2005). Do administrativismo ao empreendedorismo: a transformação da governança urbana no capitalismo tardio. In A produção capitalista do espaço (pp. 163-190). São Paulo: Anablume.

Janoschka, M. (2002). El nuevo modelo de la ciudad latinoamericana: fragmentación y privatización. EURE, 28(85), 11-20. doi: 10.4067/S0250-71612002008500002

Joao Henrique defende Capital Mundial. Disponível em http://bit.ly/Zompde

Jornal Metrópoles, 17 de junho de 2011.

Maricato, E. (2002). As idéias fora do lugar e o lugar fora das idéias. Planejamento urbano no Brasil. In O. Arantes, C. Vainer \& E. Maricato, A cidade do pensamento único (pp. 121-192) (3a ed.). Petrópolis: Editora Vozes.

Markusen, P. \& Kenpen, R.. (2000). Globalizing cities: a new spatial order? London: Backwell.

De Mattos, C. (2004). Redes, nodos e cidades: transformação da metrópole latino americana. In: L. C. Q. Ribeiro (Org.), Metrópoles. Entre a coesão e a fragmentação, a cooperação e o conflito. São Paulo: Editora Perseu Abramo; Rio de Janeiro: FASE/Observatório das Metrópoles.

De Mattos, C. (1999). Santiago de Chile, globalización y expansión metropolitana: lo que existía sigue existiendo. EURE, 25(76), 29-56. doi: 10.4067/S0250-71611999007600002

De Mattos, C. (2010). Globalización y metamorfosis metropolitana en América Latina. De la ciudad a lo urbano generalizado. Revista de Geografía Norte Grande, 47: 81-104. doi: 10.4067/ S0718-34022010000300005

De Mattos, C. (2010). Globalización y metamorfosis metropolitana en América Latina. Quito: Organización Latinoamericana y del Caribe de Centros Históricos (OLACCHI) / Município del Distrito Metropolitano de Quito.

Orgão Central de Planejamento (OCEPLAN). (1976). EPUCS: Uma experiência de planejamento urbano. Salvador, Bahia: Prefeitura Municipal do Salvador (PMS).

Pereira, G. C. (2008) Habitação e infra-estrutura urbana em Salvador e Região Metropolitana. In: I M. M. de Carvalho \& G. C. Pereira (Orgs.), Como anda Salvador. 2a ed. Salvador: Editora da Universidade Federal da Bahia (EDUFBA).

Prefeitura Municipal de Salvador (PMS). (1976). Álbum EPUCS. Salvador: Orgão Central de Planejamento (OCEPLAN) / Plano Diretor de Desenvolvimento Urbano (PLANDURB).

Prefeitura Municipal de Salvador (PMS). (2010). Salvador Capital Mundial: a cidade do nosso futuro. Salvador: PMS.

Préteceille, E. (2003) A evolução da segregação social e das desigualdades urbanas: o caso da metrópole parisiense nas últimas décadas. Caderno CRH: revista do Centro de Recursos Humanos (Salvador), 36, 27-48.

Ribeiro, L. C. Q. (Org.) (2004). Metrópole. Entre a coesão e a fragmentação, a cooperação e o conflito. São Paulo: Editora Perseu Abramo; Rio de Janeiro: FASE/Observatório das Metrópoles. 
Sabatini, F., Cáceres, G. \& Cerda, J. (2004). Segregação residencial nas principais cidades chilenas: tendências das três últimas décadas e possíveis cursos de ação. Espaço \& Debates: revista de Estudos Regionais e Urbanos (São Paulo), 24(45), 64-74.

Sampaio, A. H. (2010). 10 necessárias falas: cidade, arquitetura e urbanismo. Salvador: EDUFBA.

Sassen, S. (1991). The global city: New York, London, Tokyo. New Jersey: Princeton University Press, 1991.

Prevot-Shapira, M. F. (2000). Segregação, fragmentação, sucessão: a nova geografia social de Buenos Aires. Novos Estudos CEBRAP (São Paulo), 56, 169-183.

Souza, Â. G. (2008). Limites do Habitar, $2^{\mathrm{a}}$ ed. Salvador: Editora da Universidade Federal da Bahia (EDUFBA).

Superintendência de Controle e Ordenamento do Uso do Solo do Município (SUCOM). (07/08/2009). SUCOM firma convênio em prol do crescimento imobiliário da cidade. Disponível em http://bit.ly/11rcfbG.

Taschner, S. P. \& Bógus, L. M. M. (1999). São Paulo como Patchwork: fragmentos de uma cidade segregada. Cadernos Metrópoles (São Paulo), 1.

The Economist. (2011). .A special report in property. London: The Economist, 398(8723).

Vainer, C. (2002). Pátria, empresa e mercadoria. Notas sobre a estratégia discursiva do Planejamento Urbano. In: O. Arantes, C. Vainer \& E. Maricato, A cidade do pensamento único. $3^{\text {a }} \mathrm{ed}$. Petrópolis: Vozes.

Veiga, D. (2010). Estratificación social y desigualdades territoriales en la globalización: estudios de caso. Trabalho apresentado no XI Seminário Internacional de la Red Iberoamericana de Investigadores sobre Globalización y Territorio. Mendoza.

Veltz, P. (1996). Mondialisatiom, villes et territoires. L'economie d'archipel. Paris: Presses Universitaires de France.

Villaça, F. (2005). As ilusões do Plano Diretor. São Paulo: edição do autor. Disponível em www.flaviovillaça.arq.br

Villaça, F. (2001). Espaço Intra-Urbano no Brasil. São Paulo: Studio Nobel. 
